[Stevens, K. (2003). Open Learning to Sustain Rural Schools: The Replication of a Three-Stage Model. New Zealand Annual Review of Education, 12, 127-140]

\section{Open Learning to Sustain Rural Schools: The Replication of a Three- Stage Model}

\section{KEN STEVENS}

\section{Abstract:}

Rural schools in New Zealand and Canada have developed innovative ways of delivering education to students in small schools in remote communities using a range of technologies. Through the academic and administrative integration of classes from diverse sites, virtual educational structures and processes that complement traditional schools have developed, well-fitted to provide a template for the integration of on-site and on-line education in each country.

$\mathrm{I}$ has always been difficult to provide extensive curriculum opportunities for senior students who are reared and educated in communities that are distant from major centres of population. The advent of computers in schools, the Internet, satellite technology, twoway video conferencing, broadband initiatives, plus a growing range of learning software, have combined in New Zealand to produce new ways of teaching and learning in sparsely populated communities. Electronic educational structures and processes that have been developed in rural areas of this country have been of interest in other societies with sparsely populated regions.

In Atlantic Canada, research undertaken in rural New Zealand schools has been of particular interest, and has been applied to extend the teaching and curriculum capacities of selected schools in geographically isolated communities, known as "outports". The result of this pedagogical and technological transfer has been new learning opportunities for senior students in Canada.

This article will outline a three-stage development of the application of information and communication technologies in New Zealand rural

\section{Ken Stevens}

schools that has extended learning opportunities in this country and has been partially replicated in Atlantic Canada.

\section{A Three-stage Development of Virtual Classes in New Zealand Schools}

Telecommunications technologies have provided ways of sustaining rural educational infrastructures in several regions of New Zealand by enabling teachers and students to link with one another electronically to share resources. The development of e-learning in New Zealand took place when many rural schools were under threat of closure because of their small enrolments. A feature of telecommunications technologies in rural New Zealand schools has been the realisation by both teachers and administrators of their potential to connect one site with another, thereby challenging educational considerations of institutional size, location and access to human, curriculum and technological resources. In the interests of sustaining on-site education in rural communities, on-line education has developed at the regional level, enabling virtual classes to be created (Stevens, 1999).

By linking computers to telephone lines through modems, audio-graphic technology developed in several parts of the country. Audio-graphic teaching, as the name suggests, enables teachers and learners to hear one another and to share print and graphic material on computer screens. This elementary form of e-learning has served many small New Zealand communities very effectively. In the Canterbury region of the South Island and the north-east coast of the North Island, small rural schools have formed virtual classes to teach senior students collaboratively in a range of specialised high school subjects. When two or more schools interface electronically to combine teaching and learning, a virtual class is formed. Both teachers and students in a growing number of rural schools now have telepresences in multiple sites during the course of a school day. Three stages can be identified in the development of virtual classes in New Zealand.

(i) E-learning and the development of virtual classes in selected schools In some areas of the north-east coast of the North Island of New Zealand, the population is almost exclusively Maori and many local people speak the language fluently. Senior students in three small rural high schools north of the city of Gisborne have had considerable success in national examinations in the Maori language. However, success in other subjects for many of these students has been difficult to achieve. 
It has often been difficult to attract teachers to vacant positions in schools in this part of the country and it is not uncommon for advertised vacancies to attract few applicants. It has been particularly difficult attracting specialist teachers. In this situation it has been impossible to provide students with an on-site teacher for most subjects within each school. Many students in this region of New Zealand have, accordingly, been enrolled with the New Zealand Correspondence School, based in Wellington, for at least one of their High School courses.

To counter the disadvantage of having few on-site teachers in high schools in this part of rural New Zealand, a small, three-site electronic network was developed to share teaching resources. As well as linking with one another, each site had access to a growing range of extranets (external systems): to larger urban high schools, to polytechnics in other parts of the country, and to the New Zealand Correspondence School in Wellington. Senior students in the three small, predominantly Maori communities north of Gisborne were provided with access to each of the other two schools in the East Coast network as well as to a small range of non-local educational and vocational resources. This north-east coast network attracted the attention of educators in the South Island who collaborated in the development of virtual classes for rural communities in the southern part of the country.

\section{(ii) E-learning and the development of virtual classes in a regional intranet}

The Canterbury region of the central South Island of New Zealand contains twelve rural communities, each with its own school. With rural-urban migration, many of these communities have become smaller, and enrolments in most schools have fallen. In the last decade some schools faced closure, and parents were faced with the prospect of considerable disruption in the education of their sons and daughters.

The development of an inter-school network that became known as "Cantatech" (The Canterbury Area Schools Technology Project) brought twelve rural schools together to consider ways in which teaching and learning resources could be shared. Each school was able to provide its students with teaching in the core subjects on-site: English, Mathematics and Science, as well as instruction in one or two specialised subjects (e.g., French, Japanese, Economics, and Agriculture). By collaborating in the teaching of specialist subjects between the schools in this part of rural New Zealand, senior students who wished to receive instruction in courses not locally available have been able to access them from a participating site in the Cantatech network. By mutual consent, designated schools in the network accepted responsibility for a particular area of the curriculum in which they had a qualified teacher. In return, schools that provided specialised expertise on-line in a designated area of the curriculum could expect to receive assistance from within the network in other subjects, for the benefit of their own students. As with the North-East Coast network, the Cantatech network developed selected extranets to polytechnics and other organisations to further extend educational opportunities for rural Canterbury students.

By collaborating in the appointment of specialist teachers on each Cantatech site to avoid duplication of human resources and encourage the development of a wider range of appointments, each school in the network has been able to provide its senior students with access to an extended range of learning opportunities. Teachers appointed to any of the Cantatech schools were expected to be able to provide courses in both traditional face-to-face mode, on site, as well as on-line, as required. The development of the Cantatech network has brought about many changes in the administrative and academic life of each school. Each school in the network has had to link academically and administratively with each of the other schools, and work collaboratively in the interests of a much broader educational community than its originally-designated local one.

Because of the necessity of finding new solutions to the delivery of education to geographically isolated senior students, each school in the Cantatech network has had to consider the role of information technology in the curriculum. For teachers, students, administrators and people in each of the participating communities, information technology has become a means to enlarge local educational, and indirectly, vocational, opportunities.

E-teaching and e-learning in rural Canterbury has challenged the competitive model of schooling in New Zealand, and demonstrated the value of a collaborative, integrated virtual organisation for senior students. The Cantatech network has empowered twelve small and geographically isolated schools to deliver an extended range of subjects to senior students.

\section{(iii) Current initiatives - the move to open learning in New Zealand}

Since 1998 a National Information and Communications Technology Strategy has been developed and implemented throughout New Zealand 
(Ministry of Education, 1998). There were four objectives in the original strategy. The first objective was to improve learning outcomes through the use of ICT for teaching and learning in schools. The second was to increase the effectiveness and efficiency of teachers and schools by helping them to use ICT. The third objective was to improve the quality of teaching and leadership in schools by helping teachers and principals to identify their ICT needs and to develop the skills necessary to meet them. The final objective was to increase opportunities for schools, businesses and government to work together in developing an information technology-literate workforce.

The national strategy developed four initiatives:

(a) An On-Line Resource Centre: The On-Line Resource Centre provides teachers and schools with a mechanism for the delivery of multi-media resources, including curriculum and administration resources, using the Internet. This on-line centre is intended to support curriculum materials, provide links to curriculum experts, bilingual discussion forums, databases, multimedia and a variety of other sites. Schools have been encouraged to create their own websites and to have these placed in the on-line resource centre.

(b) A Computer Recycling Scheme: The aim of the computer recycling scheme is to enable more schools to obtain more computers for student and teacher use, at low cost. The scheme has been described as the "recycling and up-grading (of computers) in schools" (Ministry of Education, 1998, p. 12)

(c) Professional Development for Implementation and Planning: During the first year of the National Information and Communications Technology Strategy, principals and senior administrators in schools throughout New Zealand were provided with initial professional development opportunities in their local areas. These meetings focused on the use of information and communication technologies for teaching and learning..

(d) Professional Development Schools: Twenty-three schools, strategically selected from throughout New Zealand, were designated ICT professional development lead schools from late 1998. Their purpose was to assist the development of ICT in other schools within their local areas. Each lead school was chosen primarily for the ICT expertise on its staff.
Since 1998 the Ministry of Education has been engaged in a range of further initiatives to encourage e-teaching and e-learning. These include the Digital Opportunities Programme and the Kaupapa Ara Whakawhiti Matauranga (KAWM) project. Four pilot programmes within the Digital Opportunities Programme began early in 2001, based on partnerships between government and information and communications technology businesses. These included: "FarNet", which involved a community of ten schools in the north of the country, using information and communication technologies to enhance teaching and learning.; "Generation $\mathrm{XP}$ ", in which a group of eight schools in West Auckland and in the Gisborne District of the north-east coast of the North Island offered Microsoft certification courses for students; and the "Notebook Valley" programme, which focused on a group of four secondary schools in the Wellington region using notebook computers to enhance teaching and learning in mathematics and science.

The KAWM initiative began in 2000 and focused on the use of information and communication technologies to enhance teaching and learning for Maori students in schools by providing broader curriculum options. Through this initiative, Maori-medium subject specialist teachers were able to make lessons available across a number of sites.

The three stages in the development of virtual classes in New Zealand are characterised by:

- Their origins in small schools in rural communities;

- An emphasis on collaborative teaching and learning within an otherwise competitive school system;

- Co-existence of traditional print-based distance education institutions with e-learning;

- Direct government involvement in e-learning from 1998 with a range of initiatives to encourage on-line learning to complement existing educational structures and processes.

\section{A Three-Stage Partial Replication of the New Zealand Model in Atlantic Canada}

In the Canadian province of Newfoundland and Labrador, two thirds of schools are located in small, rural communities known as "outports". Over the last decade, many small schools in Atlantic Canada have been closed and students transported to larger centres. Some schools, however, are located too far from major centres of population to be 
amalgamated with other institutions, so students have had to be educated in their own small communities. These rural institutions, known as "small, necessarily-existent schools", seek to provide full K-12 education for local geographically-isolated families. With rural out-migration projected to continue since the demise of the Atlantic cod fishery and the subsequent loss of local jobs, many small schools will decrease in size. New ways have had to be found of providing educational opportunities for senior students in small and remote communities that are steadily becoming smaller. The New Zealand model has, accordingly, been of interest in this part of Canada.

\section{The Development of Virtual Classes in Canada}

The Canadian province of Newfoundland and Labrador has a predominantly rural social structure, a distinctive history and a unique culture. In the 1997-98 school year, there were 391 schools operating in the province, of which 260 , or 66 percent were located in rural communities. Thirty-one percent of schools in the province are designated "small rural schools" $(\mathrm{N}=122)$ and 75 of these had fewer than 100 students. Seventy of these small rural schools are all-grade (K-12), which means that they must offer a senior high school programme. The recent re-organisation of primary, elementary and secondary education in Newfoundland and Labrador into ten school districts provided an opportunity to develop the first digital Intranet in the province. As with e-learning in New Zealand, three stages in the development of virtual classes can be identified in this part of Canada.

\section{(i) The development of web-based science courses in selected schools}

Initially, web-based courses were introduced in selected schools in Newfoundland and Labrador in the belief that these would become "lead schools" and assist other institutions in using new technologies in teaching and learning. This initiative was countered by other schools who were attracted to the collaborative New Zealand model of clustering schools within a digital intranet. In moving from the development of web-based courses in selected schools to a more collaborative model, a decision was made to locate courses on-line to challenge senior rural students in the province.

The development of Advanced Placement (AP) Web-based courses in biology, chemistry, mathematics and physics took place within a development team in each subject area. ${ }^{1}$ In developing AP courses on-line, a lead science teacher in each discipline was paired with a recent graduate in each of biology, chemistry, mathematics and physics who possessed advanced computer skills, including web page design, Java and HTML. The lead teacher and the graduate assistant were advised from time to time by Faculty of Education specialists at Memorial University of Newfoundland in each curriculum area and, where possible, scientists from the Faculty of Science. Most course development took place through interaction between lead teachers and the recent graduates. Although at times faculty members had different opinions as to the most appropriate approach to course design, the four courses were developed over a sixteen-week summer recess period in time for the 1998-99 school year.

Minimum specifications were adopted for computer hardware and network connectivity. All schools involved in the project had DirecPC satellite dishes installed to provide a high speed down-link. In most rural communities in this part of Canada, digital telecommunications infrastructures do not enable schools to have a high speed up-link to the internet. Appropriate software had to be identified and evaluated for both the development of the resources and the delivery of instruction within the Intranet. Front Page 98 was selected as the software package. Additional software was used for the development of images, animated gifs and other dimensions of course development. These included Snagit32, Gif Construction Set, Real Video, and similar packages.

Many software packages were evaluated and finally WebCT was selected. This package enabled the instructor to track student progress; it contained online testing and evaluation, private E-mail, a calendar feature, public bulletin board for use by both instructor and student, a link to lessons, and chat rooms for communication between teacher and student. For real-time instruction, Meeting Point and Microsoft NetMeeting were selected. This combination of software enabled a teacher to present real-time interactive instruction to multiple sites. An orientation session was provided for students in June 1998, prior to the implementation of this project in September. Students had to learn how to communicate with each other and with their instructor using these new technologies before classes could begin.

\section{(ii) Teaching senior science in a school district intranet}

In eight schools within the rural Vista school district of Newfoundland and Labrador, 55 students were enrolled in AP biology, chemistry, mathematics and physics courses. While AP courses are a well-established feature of senior secondary education in the United States and Canada, it is unusual for students to be able to enrol for 
instruction at this level in small schools in remote communities. It is rare to find high school students in small and remote communities anywhere in the world who are provided with instruction in university-level studies. In Iceland (Stefansdottir, 1993), New Zealand (Stevens, 1995, 1996) and Finland (Tella, 1995) there have been attempts to provide alternative models for the delivery of education to rural students. The Vista school district initiative challenged the notion that senior students in small schools have to leave home to complete their education at larger schools in urban areas. By participating in open classes in real (synchronous) time, combined with a measure of independent (asynchronous) learning, senior students were able to interact with one another through audio, video and electronic whiteboards. At regular intervals they met to enjoy social occasions and to spend some time with their science teachers in person.

The electronic linking of eight sites within the Vista School district to collaborate in the teaching of AP biology, chemistry, mathematics and physics created a series of open classes in rural Newfoundland. The creation of the Vista School District Digital Intranet was an attempt to use information and communication technologies to provide geographically-isolated students with extended educational and, indirectly, vocational opportunities. This has been part of a broader pan-Canadian initiative to prepare people in Canada for the Information Age (Information Highway Advisory Council, 1995, 1997).

Research into the organisation of senior students who were independent learners in a networked environment in New Zealand (Stevens, 1994) preceded the formation of the Vista School District Digital Intranet in Canada. Independent learners in New Zealand were found to learn effectively, and were able to obtain satisfactory results in national examinations within an electronic network of small rural schools. In the New Zealand situation though, students usually had at least one teacher on site to assist with questions of an academic nature. In the Canadian Intranet, this was not always possible. A question facing teachers and researchers in the initial stage of the Vista School District Digital Intranet was whether students who were not used to being unsupervised could cope with new freedom and accept increased responsibility for their learning. Students were unanimous at the conclusion of the Canadian school year, that to be successful in an AP on-line course, it was necessary to be able to learn independently, cope with a high volume of work, and be willing to ask teachers and other learners questions as they arose.
It was recognised early in the 1998-99 school year that a common schedule had to be adopted throughout the school district to allow students to interact with their instructors in the new Intranet. Unfortunately, this was not fully realised until after classes commenced, with the result some instructors had to repeat classes for small numbers of students. It is anticipated that in future there will be both asynchronous as well as synchronous teaching and learning within the Intranet. The initial plan was to allow for five on-line sessions and five off-line sessions. This schedule was not followed in all schools. On-line sessions were scheduled in the morning when network traffic was at its lowest point. Off-line sessions were scheduled in the afternoon.

\section{(iii) The shift from closed to open teaching and learning in \\ Atlantic Canada}

The province of Newfoundland and Labrador has a high rate of use of satellite dishes per capita, and there are many schools in this province with Local Area Networks (LANs). As a province, Newfoundland and Labrador provided excellent opportunities for the development of these technologies.

Students in the Vista School District Digital Intranet were frequently subject to scrutiny by their peers as they responded through chat-rooms, audio, video and with their AP on-line teacher. The Digital Intranet provided students with access to multiple sites simultaneously, as well as the opportunity to work independently of a teacher for part of the day. The need to prepare for classes before going on-line became increasingly apparent to both teachers and students if the open, synchronous, science classes were to succeed. The advent of the Digital Intranet had implications for students who had to interact with teachers and their peers in a variety of new ways. The teaching of each of the four AP Science disciplines in the Vista School District Digital Intranet took place within classes that were open between participating sites. Many students experienced difficulty expressing themselves and, in particular, asking questions in open electronic classes, when they did not know their peers from other small communities. The organisation of social occasions for students learning science in open classes in the Intranet helped overcome these problems. As students became more comfortable with one another, inhibitions such as asking questions on-line were overcome. Future interaction in the Vista School District Digital Intranet will be both synchronous and asynchronous.

The major change for the students in the first Digital Intranet in Newfoundland and Labrador however, has been the opportunity 
provided to study advanced science subjects, as members of open classes, from their small, remote communities. A Digital Intranet has many implications for the management of education, based on the need to ensure all sites collaborate both academically and administratively. The most important administrative issue in the first year of the Vista School District Digital Intranet has been the co-ordination of timetables across participating sites.

The need for increased technical support for this new, open structure has become increasingly urgent for teachers and students who are using information and communication technologies to teach and learn across dispersed sites. Both have to be provided with expert advice and instruction in the use of new applications. A particular problem has been difficulty in securing and maintaining instructional design expertise in the preparation and upgrading of courses delivered through the Intranet.

Following a ministerial inquiry into what became known as "distance education in classrooms" in rural Newfoundland and Labrador schools, a decision was made by the provincial Department of Education to accelerate and extend the development of school district digital intranets. Within the Department of Education of Newfoundland and Labrador, a Centre for Distance Learning and Innovation was established to promote on-line learning within and between new electronic educational structures throughout the province.

\section{Educational and Policy Implications}

Although Canada and New Zealand differ in terms of geography and the size of their respective populations, both societies have many communities located considerable distances from major centres of population. Their resource-based economies necessitate having sustainable rural communities and a key institution in achieving this is the local school.

In both New Zealand and Canada rural schools have developed innovative technological practices, through which senior high school students have been provided with extended access to learning opportunities. In both countries e-learning in rural communities began in single schools which linked to form regional teaching and learning networks from which national (New Zealand) and provincial (Canadian) strategies have emerged.

The significance of the parallel development of rural school e-learning in New Zealand and Canada has been primarily for the institutions and the communities that they serve. Nevertheless, in seeking to extend educational opportunities for senior students in small schools in rural communities, new teaching and learning structures have emerged in both countries in the form of school district digital intranets within which virtual classes have developed.

In each society there is now a challenge to develop pedagogy that is appropriate for the integration of on-site and on-line teaching and learning(Stevens \& Moffatt, 1996, 2003). New educational professionals are emerging in Canada: e-teachers (who teach through the Internet), m-teachers (who mediate on-site between e-teachers and local students) and instructional designers. ${ }^{3}$

As well as extending the educational opportunities of senior students in small schools, the pioneering nature of inter-school teaching and learning in Canada and New Zealand has implications for the teaching profession, for the delivery of courses, for the organisation of classrooms and schools and for the funding of education. As schools in rural New Zealand and Canada open to one another academically and administratively, the question arises for teachers, students and, above all, administrators: what is a school in the twenty-first century?

Notes

1. AP courses enable senior students to begin undergraduate degrees with part of their program completed from high school, if courses are passed at grade levels specified by the university of their choice. Until this initiative, AP courses had not been taught on-line or in rural schools in either Canada or the United States.

2. The Vista School District (District 8) contains 18 schools ranging in student enrolment from 40 to 650 . The region in which the Vista School District is located extends from Bonavista in the north, (the place where John Cabot landed in North America in 1497) to the Burin Peninsula in the south. It is a large geographic area covering about 7000 square kilometres. The region has a population of about 35,000 people and an economy supported by a diverse infrastructure including fishing, forestry, farming, mining, aquaculture and tourism. The Vista School District was formed in 1996 and became a legal entity in January 1997. There were 5165 students enrolled in the 18 schools in the district, taught by 366 teachers. The Vista School District is approximately two hours by road from the capital city, St Johns, which is the location of Memorial University of Newfoundland. Eight schools within the Vista School district, together with the TeleLearning and Rural Education Centre of Memorial University of Newfoundland, formed a digital Intranet within which senior science courses were taught in open classes. 
3. The author, who is a New Zealander living in Canada, has initiated brief on-line exchanges between teachers in each country and this has opened pedagogical issues about the use of time zones in teaching and learning.

\section{References}

Information Highway Advisory Council. (1995). The challenge of the information highway. Ottawa, Industry Canada.

Information Highway Advisory Council. (1997). Preparing Canada for a Digital World. Ottawa: Industry Canada.

Ministry of Education. (1998). Interactive education - an information and communication technologies strategy for schools. Wellington: Ministry of Education.

Stefansdottir, L. (1993). The Icelandic educational network-Ismennt. In G. Davies \& B. Samways (Eds.), Teleteaching - Proceedings of the IFIP TC3 Third Teleteaching Conference (pp. 829-835). Amsterdam: Elsevier Science Publishers.

Stevens, K. J. (1994). Some applications of distance education technologies and pedagogies in rural schools in New Zealand. Distance Education, 15(4), 318-326.

Stevens, K. J. (1995). Geographic isolation and technological change: A new vision of teaching and learning in rural schools in New Zealand. The Journal of Distance Learning, 1(1), pp. 32-38.

Stevens, K. J. (1996). The technological challenge to the notion of rurality in New Zealand Education - repositioning the small school. New Zealand Annual Review of Education, 5, 93-102.

Stevens, K., \& Moffatt, C. (1996). TeleLearning and New Zealand secondary schools - some pedagogical and management issues in the development of courses for flexible delivery. Paper presented at the Technology for Flexible Delivery Conference, Massey University, Palmerston North.

Stevens, K. (1999). Telecommunications technologies, telelearning and the development of virtual classes for rural New Zealanders. Open Praxis, 1, 12-14.

Stevens, K., \& Moffat, C. (in press) From distance education to elearning - The organization of open classes at local, regional and national levels. In J. Bradley (Ed.), The open classroom - Distance learning in schools. London: Kogan Page.

Tella, S. (1995). Virtual school in a networking learning environment, Helsinki: University of Helsinki, Department of Teacher Education.

\section{The author}

Ken Stevens is a New Zealander who is Professor of Education at Memorial University of Newfoundland, Canada where he holds the Chair of TeleLearning and Rural Education, a research position established with assistance from Industry Canada. His previous appointments were at Victoria University of Wellington and James Cook University in Queensland, Australia. Since taking up his Canadian appointment he has been engaged in developing new educational structures and processes to link schools in small and often isolated communities, using the Internet to enable them to share resources and expertise in specialised areas of the curriculum.

Email:stevensk@mun.ca 